\title{
Comment on Goeschl: Do patent-style intellectual property rights on transgenic crops harm the environment?
}

\author{
Henk Hogeveen ${ }^{\#}$ and Tassos Michalopoulos $\#$
}

\section{Introduction}

Intellectual property rights (IPR) are known to be an effective institution for providing people with incentives to create, maintain and improve assets. However, in the breeding of live organisms (plants as well as animals) IPR did not play an important role. In plant breeding there was an institution known as breeder's rights to prevent copying. Following the introduction of biotechnological research into breeding, the role of IPR became more important, for both traditional and biotechnological breeding technologies. Two subsequent GATT/WTO agreements (Uruguay 1993 and TRIPS agreement) brought agriculture and trade-related intellectual property rights to fall under the mandate of the free-market regulations. Consequentially, governments tend to withdraw from the R\&D process and transfer the R\&D-stimulating role to the private sector. This means that IPR become even more important. As Goeschl has stated, in the discussions with regard to biotechnological developments (including transgenic crops) IPR play an important role. Part of this role is based upon the fundamental question whether life can be patented. In this comment, however, the relation between IPR in plant breeding and effects of plant breeding on the environment will be discussed. In order to do this, the role and incentives of the stakeholders in this field should be examined. Using these roles, the effects of IPR in research and development (R\&D) with regard to plant breeding can be discussed.

\section{Roles of stakeholders}

Around the discussion on IPR, genetic modification, environment and R\&D, the following stakeholders can be distinguished: government, consumer, breeding company, farmer and research institute. The role and incentives for these stakeholders will be discussed in the line of a western, capitalist society.

\section{Government}

The main goal of the government (ideally) is to safeguard the interest of the whole society. To achieve this the government will (try to) establish a minimum level of welfare for all inhabitants of a country. This means that business activity is necessary to generate income. The environment (natural resources) provides part of

\footnotetext{
\# Farm Management Group, Wageningen University, Hollandseweg 1, 6706 KN Wageningen, The Netherlands. E-mail: henk.hogeveen@wur.nl

\#\# Applied Philosophy Group, Wageningen University, Hollandseweg 1, 6706 KN Wageningen, The Netherlands. E-mail: tassos.michalopoulos@wur.nl
} 
the welfare, and therefore maintaining or even improving the environment is considered part of the responsibility of the government. The government can stimulate a proper direction of society by making regulations or by stimulating the appropriate development by subsidies, R\&D investments etc.

\section{Breeding company}

The main goal of each private company is to create shareholder value. Those who invest in a company want a return on their investment, either by an increasing value of their shares or by dividend. A company can do so by creating successful competitive products (price increase), adopting strategies that will increase its market share, and by means of reduction of production costs. Improving products or production processes by R\&D can help to reach the goals, especially when the rights to use these products or production processes are protected by IPR. However, a (breeding) company will not directly care about negative side effects (for instance on the environment). Only if their products harm the environment in such a way that it will negatively influence the image and in the long run the market share of a company, will the environment become of interest.

\section{Farmers}

From a business-economics point of view, almost all farms are losing money. Therefore, the goal of a farmer (most farms are family farms) can be seen as to continue being a farmer and to make enough money to support the family. From that point of view, they want their costs, including costs for their crops, as low as possible, with a price for their own products as high as possible. When they spend more money on new breeds, they expect to earn that money back, either by lower costs in crop production or by higher prices because of the higher quality of their products. The decision which crop to use, is taken by each individual farmer, given the place of the farmer in the production chain. However, because of their number, farmers can directly influence neither the price structure, nor the selection of the technologies to be adopted. In that way, wishing to maintain an income adequate to cover his financial needs and subsequently to be able to remain within the farming practice, the farmer is feeling pressure to keep himself as close to the frontier as possible. The tendency of an IPR-regulated system for adopting a subsequent rather than a parallel mode of technology adaptation as remarked in the commented paper, enforces this process. That is, as the subsequent mode of technological adaptation is chosen due to its better financial perspectives for the breeding companies, while it might fail to cope with the response of the biological system (e.g. widespread development of resistance).

\section{Consumers}

The interest of the consumer is to pay the lowest price for a product with a certain quality. Breeding-technology progress often has a direct impact on lowering product prices. Concerning quality, there are three quality aspects involved: sensory aspects (taste, size, colour etc.), safety aspects (possible chemical or bacteriological contamination) and intrinsic aspects (the way a product is produced, i.e., harm for the environment). For each of these quality aspects there is a production function: how much is a consumer willing to pay for a better taste, for a safer product or for a product produced in an environmentally friendly way? However, this function is not merely an object of observation for the producers, as effective marketing strategies often aim precisely at increasing this margin. 


\section{Research institutes}

Research institutes need money in order to carry out research. The incentives of researchers are not only financial, but also the 'honour' to publish (scientific) papers and the status it gives in the international research community. This is especially the case with fundamental, curiosity-driven research, which has the role to clarify our knowledge of the 'world'. This fundamental research may never be applied, but the knowledge is shared and publicly available. With more applied research, the goal is either to develop new directions for new technologies or products, or to study the effects of these new directions on economy, welfare, environment etc. The IPR on research results may be used to generate money for new developments. An asymmetry that has to be noted, however, is that while applied research is usually based on (some of) the outputs of previously done, publicly available (and usually publicly funded) fundamental research, under the notion of IPR the knowledge it produces is private.

\section{Flow of products and money in various scenarios}

In this section two (extreme) scenarios with regard to IPR and R\&D will be described:

1. A public system; there are no IPR possible on breeds.

2. A private system; IPR are intensively used and because of that the government withdraws from R\&D activities.

These two extreme situations are described under the assumption that a constant amount of R\&D is done in order to establish progress.

\section{Public system}

In a situation where private $R \& D$ expenditures cannot be covered by IPR (or something like a breeder's right) there will be very little incentive for breeding companies to invest in R\&D. The only advantage from investments will be during a short period after introduction. After that, other breeding companies will soon be able to introduce the same variety. This means that the government will pay for almost all R\&D. Results of this R\&D will be publicly available and all breeding companies are able to utilize the new knowledge. Competition between companies will be the result and breeding material will be relatively cheap for the farmer. Consequently, the price of the end product for the farmer will be low. Prices for the consumer can also stay low. On the other hand, the money the government spends on R\&D must also be acquired. That means that the taxpayers (often also consumers) have to pay higher taxes.

In an ideal situation, the government will not only pay for the development of improved breeds, but also for possible side-effects of new technologies, for instance effects on the environment. This information can lead to new regulations to protect the environment.

With the current globally operating breeding companies, there is one major disadvantage, which is the flow of money from country to country. If the government of one country spends money on R\&D, the companies, farmers and consumers of another country also benefit, which means that different countries should share R\&D expenditures. In this sense, a 'National Breeder's Right' may prove to be required.

Furthermore, questions can be raised as to whether the public sector can show the necessary management and marketing skills to be regarded equal to those in the private sector in terms of production efficiency. 


\section{Private system}

When the government does not pay for R\&D in plant breeding, investments of private companies should be made worthwhile by some kind of IPR system. In such a system the breeding company pays for the R\&D, either by its own research or by financing a research institute to conduct research on its behalf. The company will earn that investment back by means of an increased price of the breeding material. The farmer will adopt the new product in order to enjoy its increased advantages, the more so because if he chooses to do otherwise he may have a production disadvantage in comparison with other farmers who do adopt it. When the advantages are great enough, the farmer will pay this higher price. In case of the improvement of production, the benefits of cheaper production should be enough to make up for the higher price of breeding material. However, the profit increase for the farmer will be lower than in the public system. On the other hand, if the quality of the products increases, the consumer has to make up for the increase in price of the breeding material. Hence, the prices for the consumer will be higher than in the public system. This can be explained by the fact that the private sector aims at profit optimization, while for the public sector societal welfare is expected to be the main mandate, requiring a sustainable $R \& D$ sector, but moderating profit expectations.

As a consequence of this private system, there will hardly be any R\&D into sideeffects of new technologies, unless demanded by the consumers/market. There is no incentive for private companies to do otherwise. It is possible that breeding material might harm the environment. This lack of R\&D into side-effects might be made up for by regulations such as for the pharmaceutical industry (cf. the FDA in the US), where in order to get a registration (and thus the right to sell a product) the company must show that the product is safe. This type of regulation builds on known types of sideeffects. New side-effects are found by application of the new product. This means that damage could already be done before regulation is adjusted. More than this, while the private sector is the one that enjoys the profit of marketing its products, it is the public sector that carries the burden of restoring potential - unexpected - harmful sideeffects. A possible way out of this perspective, would be to make the private sector responsible for restoring any harm produced as a side-effect of its production, whether it was unexpected or not. Such an approach would result in increased testing prior to marketing, less side effects, but higher product prices.

\section{Concluding remarks}

The two extreme and very simple scenarios described above are very simple examples of the real situation. Neither of these scenarios exists. The current situation is a mixture between both extremes. However, there is a tendency towards the private system, which is supported by the WTO agreements on agriculture and IPR. The two examples demonstrate that $R \& D$ in progress in plant breeds, whether it is financed by the government (public sector) or by breeding companies (private sector) is in the end going to be paid for by the society (consumers and/or farmers). There are possible reasons that the private system is more efficient in the R\&D process and in thinking of the demands of consumers and farmers than the public system. The private system can prove to have harmful impacts on aspects such as the environment and societal structure as long as these aspects keep on being regarded as side-effects of the supply chain (indirectly linked to its scope via consumers' demands), and keep on not being included directly in its targets, next to profit optimization. Possible ways for avoiding potential harmful impacts resulting from this situation would be the increase of 
public-sector involvement in plant breeding, or the creation of adequate incentives for the private sector to be more focused on possible side effects.

Finally we should be aware that the discussion with regard to IPR in breeding is much wider than the scope of this comment. The ethical question on the possibility to patent life, the difficulties for developing countries with regard to IPR, the societal implications that arise due to dismissing traditional farming practices (seed saving, versus dependency on breeding companies), and the inefficiency involved when patents from various companies have to be added together form another aspect of the discussion. 